\title{
2-(4-Diethylaminostyryl)-1,3,3-trimethyl-5-thiocyanato-3H-indolium chloride as a new reagent for indirect spectrophotometric red-ox determination of Osmium (VI)
}

\author{
Zholt Kormosh, Svitlana Korolchuk \\ Volyn National University, Department of Analytical Chemistry, Voly av., 13, 43021 Lutsk, Ukraine, phone: +380332248427 , \\ e-mail:kormosh@univer.lutsk.ua
}

\begin{abstract}
A highly sensitive indirect spectrophotometric redox method for the determination of osmium is reported on. The method is based on the oxidation of iodide by osmium (VI) and the spectrophotometric detection of the liberated iodine in the form of complex anion associate with 2-(4-diethylaminostyryl)-1,3,3-trimethyl5 -thiocyanato- $3 \mathrm{H}$-indolium chloride reagent. The appropriate reaction conditions have been established. The molar absorptivity is $(0.2-1.2) \cdot 10^{5} \mathrm{dm}^{3} / \mathrm{mol}^{-} \mathrm{cm}$ at $589.5 \mathrm{~nm}$ wavelength. The absorbance of the coloured extracts obeys the Beer's law in the range to $7.6 \mathrm{mg} / \mathrm{dm}^{3}$ of Os(VI).
\end{abstract}

Keywords: Osmium, determination, spectrophotometry.

\section{INTRODUCTION}

The accurate determination of platinum group metals in various matrices is one of the most difficult analytical problems. A large variety and complexity of the examined materials, inhomogeneous distribution of metals in the examined samples and a wide range of concentrations to be determined make the choice of the analytical procedure to the used a fundamental problem. Direct use of instrumental techniques for the determination of noble metals is considerably restricted owing to numerous interferences caused by various types of matrices ${ }^{1-3}$.

UV-VIS spectrophotometry was historically the first instrumental technique used for the quantification of small amounts of noble metals in various materials. The technique requires a quantitative conversion of the analytes into stable complexes that can act as the basis of spectrophotometric measurements ${ }^{4}$.

The polymethine dyes group includes organic compounds, which are characterized by the presence of the conjugate bonds chain, consisting of methine groups with the electron-donor and -acceptor radicals of the general formula $\left[\mathrm{R}_{1}-(\mathrm{CH}=)_{\mathrm{n}}-\mathrm{R}_{2}\right]^{+} \mathrm{X}^{-}\left(\mathrm{X}^{-}-\right.$inorganic or organic counterion; $n=2,3$ ). Such compounds have a set of original properties and are rather widespread in different fields of science and engineering. The acid-base properties and the main spectrophotometric characteristics of some dyes were investigated ${ }^{5,6}$. The advantages of some polymethine dyes as the analytical reagent are stability and high value of molar absorptivities.

The aim of this work was to investigate the new polymethine dye, 2-(4-diethylaminostyryl)-1,3,3-trimethyl5-thiocyanato-3H-indolium chloride (DEST):

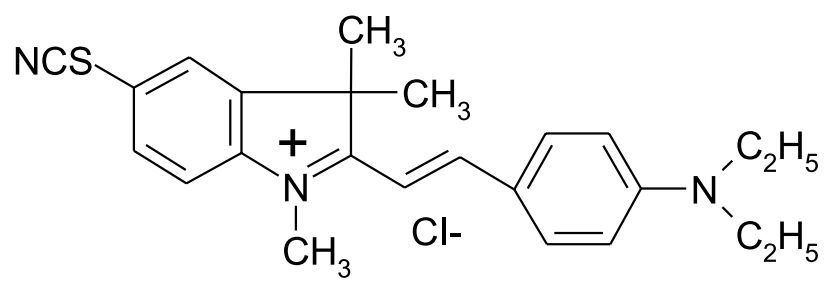

for the spectrophotometric red-ox determination of osmium (VI).

\section{EXPERIMENTAL}

\section{Apparatus}

The SF-2000 UV VIS scanning spectrophotometer (LOMO, Russia) with the matched quartz cells of 1 to 10 $\mathrm{mm}$ path length was used for recording the complete absorption spectra. The I-160 $\mathrm{M}$ ionometer with a glass electrode was used for measuring the $\mathrm{pH}$ values of aqueous solutions.

\section{Reagents and solutions}

All the chemicals and solvents used were of analytical reagent grade. Double distilled water was used throughout the process. A stock $0.01 \mathrm{~mol} / \mathrm{dm}^{3}$ solution of osmium (VI) was prepared by the dissolution of $\mathrm{K}_{2} \mathrm{OsO}_{4} \cdot 2 \mathrm{H}_{2} \mathrm{O}$ (ALDRICH) in $3.0 \mathrm{~mol} / \mathrm{dm}^{3} \mathrm{KOH}$. Because of their lower stability, the working solutions of the concentration range $10^{-5}$ to $10^{-4} \mathrm{~mol} / \mathrm{dm}^{3}$ were prepared by diluting the stock before use. The $10^{-3} \mathrm{~mol} / \mathrm{dm}^{3}$ aqueous solution of DEST was prepared from its chloride salt. The acidity of the solution was adjusted using sulfuric or phosphoric acid. The required concentration of iodide was reached using $0.05 \mathrm{~mol} / \mathrm{dm}^{3}$ sodium iodide. The necessary concentration of ligand was set by the addition of $0.1 \mathrm{~mol} / \mathrm{dm}^{3}$ potassium bromide. The following organic solvents were tested as extractants: hexane, benzene, toluene and butyl acetate.

\section{Synthesis and property of dye}

The synthesis of DEST was carried out according to the guidelines ${ }^{7,8}$ by the condensation of the 4diethylaminobenzaldehyde with the 1,3,3-trimethyl-5thiocyanato-3H-indolium chloride in dry acetic anhydride. The reaction mixture was boiled in a flask under the reflux condenser for $1-5$ minutes. The flask was cooled, and then the distilled water was added (for the hydrolysis of the rest of acetic anhydride). The obtained dye was precipitated by diethyl ether; salting out by saturated $\mathrm{KCl}$ solution was additionally used. Dye crystals were filtered, washed with diethyl ether, benzene and recrystallized from acetone or methanol. The purity of dye was estimated by thin-layer chromatography on „Silufol UV-254” plates, 
using a mixture of butanol-1: acetic acid: water (4:1:5) as a mobile phase. The dyes identified by the UV-, VIS-, IRand ${ }^{1} \mathrm{H}$ NMR - spectroscopy.

The investigation of the state of the DEST in aqueous solutions shows that it has intensive coloring with a maximum of absorption at $573 \mathrm{~nm}$ in neutral and low acidity media. The coloring of the dyes fades in high acidity or alkalinity of the media. Protonation constants were determined by the spectrophotometry method. Samples with different serial acidity of the medium were prepared. Figure 1 shows that light absorption of DEST solutions depends on the media acidity. Three maximums correspond to the different forms of a dye - ionic $\left(\mathrm{R}^{+}, \mathrm{HR}^{2+}\right)$ and hydroxylated $(\mathrm{ROH})$. The $\mathrm{R}^{+}$form dominates in an interval $\mathrm{pH}$ from 3 up to 10 and gives rise to the absorption maximum at $573 \mathrm{~nm}$. While increasing the acidity, the single-charged $\mathrm{R}^{+}$is protonated.

The spectrophotometric characteristics of the different forms of dyes and their protonation constants are as follows: $\mathrm{R}^{+}-\lambda_{\text {max. }}=573 \mathrm{~nm}, \varepsilon_{573}=73000 \mathrm{dm}^{3} / \mathrm{mol} \mathrm{cm}$; $\mathrm{HR}^{2+}-\lambda_{\text {max. }}=381 \mathrm{~nm}, \varepsilon_{381}=21000 \mathrm{dm}^{3} / \mathrm{mol} \mathrm{cm}$; $\mathrm{ROH}-\lambda_{\text {max. }}=306 \mathrm{~nm}, \varepsilon_{306}=26000 \mathrm{dm}^{3} / \mathrm{mol} \mathrm{cm}$; $\mathrm{pK}_{\mathrm{a}}=2.15, \mathrm{pK}_{\mathrm{b}}=11.33$.



Figure 1. The absorption spectrum of different forms of DEST

\section{Procedure}

A necessary amount of Os(VI) was added to the separation funnels. The volume was diluted with water and the required acidity of the solution and the required iodide concentration were reached. The total volume of the aqueous phase was $5 \mathrm{~cm}^{3}$. After the addition of each chemical, the solution was mixed. Next, the solution was left to stand for $5 \mathrm{~min}$. The liberated elemental iodine was extracted by $5 \mathrm{~cm}^{3}$ of the organic solvent for $1 \mathrm{~min}$. The organic phase was separated into the test tube containing the required concentration of bromide ligand and the dye reagent, and the formed dye salt with complex counterion was extracted for $30 \mathrm{~s}$. All procedures were realized at room temperature. After the phase separation, the absorbance of the organic phase was measured. At the same time, the measurement of the blank test was realized.

\section{RESULTS AND DISCUSSION}

The preliminary experiments show that Os (VI) forms no extractable complex anions with the tested dye. Nevertheless, the indirect determination of osmium based on the oxidation of iodide by osmium (IV) and spectrophotometric detection of the formed iodine in the form of the complex anion and associate with the investigated dye, is possible.

The osmium (VI) with iodide to form iodine

$\mathrm{Os}(\mathrm{VI})+2 \mathrm{I}^{-} \rightarrow \mathrm{Os}(\mathrm{IV})+\mathrm{I}_{2}$

The optimum conditions for the red-ox reaction were determined: $0.5-1.0 \mathrm{~mol} / \mathrm{dm}^{3} \mathrm{H}_{3} \mathrm{PO}_{4}, 0.01-0.10 \mathrm{~mol} /$ $\mathrm{dm}^{3} \mathrm{KI}$ and reaction time $5 \mathrm{~min}$. The liberated iodine is extracted into toluene

$\mathrm{I}_{2(\mathrm{aq})} \rightarrow \mathrm{I}_{2 \text { (org) }}$

The ion associate (IA) is formed and extracted $\mathrm{I}_{2 \text { (org) }}+\mathrm{Br}_{(\mathrm{aq})}^{-}+\mathrm{DEST}^{+}{ }_{(\mathrm{aq})} \rightarrow\left[\mathrm{I}_{2} \mathrm{Br}^{-}\right] \mathrm{DEST}^{+}{ }_{(\text {org })}$

In order to find the optimum conditions for complex formation and extraction, the influence of medium acidity, the concentration of bromide ions and dye reagents, and the nature of the extractants on the absorbance of colored extracts were all investigated.

The optimum conditions for the extraction of $\left[\mathrm{I}_{2} \mathrm{Br}^{-}\right]$ ion associate with DEST were determined: the acidity of the solution ranges from $\mathrm{pH} 3$ to $\mathrm{pH} 9$, the concentration of $\mathrm{Br}^{-}$- ions ranges from 0.01 to $0.03 \mathrm{~mol} / \mathrm{dm}^{3}$ and from 0.0007 to $0.0014 \mathrm{~mol} / \mathrm{dm}^{3}$ of DEST. Benzene, toluene and xylene turned out to be the best extractants.

The equilibrium of the extracted colored salt with complex anion is established within $30 \mathrm{~s}$ and the color is stable for several hours. The molar absorptivity is (0.21.2) $\cdot 10^{5} \mathrm{dm}^{3} / \mathrm{mol} \cdot \mathrm{cm}$ (Table 1 ) at $589.5 \mathrm{~nm}$ wavelength. The absorbance of the colored extracts obeys the Beer's law in the range to $7.6 \mathrm{mg} / \mathrm{dm}^{3}$ of Os (VI).

Table 1. The main characteristics of extracted IA

\begin{tabular}{|l|c|r|r|r|r|}
\hline Organic solvent & $\lambda_{\max }, \mathrm{nm}$ & $\varepsilon, 10^{4}$ & $\mathrm{~A}_{K} / \mathrm{A}_{\mathrm{R}}$ & \multicolumn{1}{c|}{$\mathrm{R}, \%$} & \multicolumn{1}{c|}{$\mathrm{D}$} \\
\hline Toluene & 589.5 & 7.0 & 40.2 & 96.8 & 30.3 \\
\hline o-Xylene & 581.2 & 2.1 & 5.2 & 56.5 & 4.3 \\
\hline Benzene & 585.9 & 11.8 & 9.6 & 89.2 & 8.3 \\
\hline
\end{tabular}

$A_{K}$ - absorbance of IA, $A_{R}$ - absorbance of blank test,

$R$ - percent of extraction, $D$ - distribution ratio

The determination of osmium (VI) does not interfere with alkali metals, $\mathrm{Cl}^{-}, \mathrm{PO}_{4}{ }^{3-}, \mathrm{SO}_{4}{ }^{2-}, 2500$-fold quantities of $\mathrm{Al}(\mathrm{III}), \mathrm{Zn}$ (II), $\mathrm{Cr}$ (III), Ni(II), $\mathrm{Co}(\mathrm{II}), \mathrm{Mn}$ (II), 200fold quantities of $\mathrm{Cd}(\mathrm{II}), \mathrm{Te}(\mathrm{IV}), 40$-fold quantities of $\mathrm{Pb}(\mathrm{II}), \mathrm{Cu}(\mathrm{II})$, and 10-fold quantities of $\mathrm{Bi}(\mathrm{III})$. The strong oxidants (Mn(VII), $\mathrm{Cr}(\mathrm{VI}), \mathrm{Cl}(\mathrm{V}), \mathrm{Cl}(\mathrm{II}), \mathrm{Fe}(\mathrm{III}), \mathrm{O}_{3}$, $\mathrm{H}_{2} \mathrm{O}_{2}$ interfere with the determination of osmium (VI).

The suggested method was applied for the determination of osmium (VI) in model solutions with satisfactory results (Table 2 ).

Table 2. Osmium determination in model solutions $(n=5$, $P=0.95)$

\begin{tabular}{|c|c|c|c|}
\hline \multirow{2}{*}{ Sample } & \multirow{2}{*}{ Add Os $(\mathrm{VI}), \mu \mathrm{g}$} & \multicolumn{2}{|c|}{ Found Os(VI), $\mu \mathrm{g}$} \\
\cline { 3 - 4 } & 2.5 & $\mathrm{X} \pm \Delta \mathrm{X}$ & $\mathrm{RSD}$ \\
\hline 1 & 4.2 & $2.6 \pm 0.1$ & 3.5 \\
\hline 2 & 7.2 & $4.2 \pm 0.1$ & 2.3 \\
\hline 3 & $7.2 \pm 0.3$ & 2.8 \\
\hline
\end{tabular}




\section{LITERATURE CITED}

1. Balcerzak, M. \& Wyrzykowska, E. (1999). Extraction preconcentration of platinum and ruthenium using high molecular weight amines prior to simultaneous determination by derivative spectrophotometry. Analusis, 27, $829-834$. DOI: 10.1051 /analusis:1999150.

2. Beamish, F. E. (1966). The Analytical Chemistry of the Noble Metals, New York, Pergamon.

3. Zolotov, Yu.A., Varshal, G.M. \& Ivanov, V.M. (2003). Analyticheskaya khimiya metallov platinovoi gruppy (Analytical Chemistry of Platinum-Group Metals), Moscow, Editorial URSS.

4. Balcerzak, M. (2002). Sample Digestion Methods for the Determination of Traces of Precious Metals by Spectrometric Techniques. Anal. Sci. 18(7), 737 - 750. DOI:10.2116/analsci.18.737

5. Balogh, I.S., Kish, P.P., Ishchenko, A.A., Mushkalo, I.L. \& Andrukh, V.A. (1999). Spectrophotometric study of acidbase properties of cationic cyanine dyes. J. Anal. Chem. 45 (3), 481 - 489.

6. Kormosh, Zh., Bazel, Ya. \& Tolmachov, A. (2002). The state and chemical-analytical properties of certain polymrthine dyes in aqueous solutions. Acta Chim. Slov. 49(4), 795 - 804. http://acta.chem-soc.si/49/49-4-795.pdf.

7. Chunayev, Yu.M., \& Przhiyalgovskaja, N.M. (1990). The basis of the 2-methylindolinium. Synthesizing and properties. The Totals of Science and Engineering, 14, Moscow. VINITI

8. Tolmachov, A.A., Tolmachova, S.V., Shevchuk, L.I., Turov, A.V., Kozlov, É. S. \& Babichev, F.S. (1990). Substituted 2-methyl- and 2-methyleneindolines. 3. Nitroamino5,6-disubstituted 2-methyl- and 2-methyleneindolines. Chem. Heterocycl. Comp. 26 (11), 1245 - 1249. http:// www.springerlink.com/content/v625126333775161/fulltext.pdf 